\title{
Rapid and Sensitive Detection of Salmonella in Chickens Using Loop-Mediated Isothermal Amplification Combined with a Lateral Flow Dipstick ${ }^{\mathrm{s}}$
}

\author{
Zhi-Ke Liu ${ }^{1}$, Qiu-Yu Zhang ${ }^{2}$, Ning-Ning Yang ${ }^{1}$, Ming-Guo Xu ${ }^{1}$, Jin-Feng $\mathrm{Xu}^{3}$, Ming-Long Jing ${ }^{1}$, Wen-Xing $\mathrm{Wu}^{1}$, \\ Ya-Dong $\mathrm{Lu}^{1}$, Feng $\mathrm{Shi}^{3,4 *}$, and Chuang-Fu Chen ${ }^{1,5 *}$ \\ ${ }^{1}$ College of Animal Science and Technology, Shihezi University, Shihezi 832000, P.R. China \\ ${ }^{2}$ College of Animal Science and Technology, Henan Institute of Science and Technology, Xinxiang 453003, P.R. China \\ ${ }^{3}$ College of Life Sciences, Shihezi University, Shihezi 832000, P.R. China \\ ${ }^{4}$ Nucleic Acids Labeling and Detecting Lab, Key Laboratory of Ministry of Education with Provincial Co-Construction of Local and Ethnic \\ High Incidence in Xinjiang, Shihezi 832000, P.R. China \\ ${ }^{5}$ Co-Innovation Center for Zoonotic Infectious Diseases in the Western Region, Shihezi University, Shihezi 832000, P.R. China
}

Received: December 6, 2017
Revised: March 16, 2018
Accepted: March 21, 2018
First published online
April 6, 2018
*Corresponding authors
C.C.
Phone: +86-993-2058-002;
Fax: +86-993-2058-612;
E-mail: ccf-xb@163.com.
F.S.
Phone: +86-993-2057-262;
Fax: +86-993-2057-216;
E-mail: shifeng2314@yeah.net

S upplementary data for this paper are available on-line only at http://jmb.or.kr.

pISSN 1017-7825, eISSN 1738-8872

Copyright(C) 2019 by

The Korean Society for Microbiology and Biotechnology

\begin{abstract}
Salmonellosis is a highly contagious bacterial disease that threatens both human and poultry health. Tests that can detect Salmonella in the field are urgently required to facilitate disease control and for epidemiological investigations. Here, we combined loop-mediated isothermal amplification (LAMP) with a chromatographic lateral flow dipstick (LFD) to rapidly and accurately detect Salmonella. LAMP primers were designed to target the Salmonella invA gene. LAMP conditions were optimized by adjusting the ratio of inner to outer primers, $\mathrm{MgSO}_{4}$ concentration, dNTP mix concentration, amplification temperature, and amplification time. We evaluated the specificity of our novel LAMP-LFD method using six Salmonella species and six related non-Salmonella strains. All six of the Salmonella strains, but none of the nonSalmonella strains, were amplified. LAMP-LFD was sensitive enough to detect concentrations of Salmonella enterica subsp. enterica serovar Pullorum genomic DNA as low as $89 \mathrm{fg} / \mu \mathrm{l}$, which is 1,000 times more sensitive than conventional PCR. When artificially contaminated feed samples were analyzed, LAMP-LFD was also more sensitive than PCR. Finally, LAMP-LFD gave no false positives across 350 chicken anal swabs. Therefore, our novel LAMP-LFD assay was highly sensitive, specific, convenient, and fast, making it a valuable tool for the early diagnosis and monitoring of Salmonella infection in chickens.
\end{abstract}

Keywords: Salmonella, invA gene, loop-mediated isothermal amplification, lateral flow dipstick, detection

\section{Introduction}

Salmonellosis in chickens is caused by Salmonella, a common zoonotic pathogen. This pathogen poses a serious threat to China's socio-economic and public health [1]. The number of Salmonella-related deaths and infections increases every year; therefore, salmonellosis is an important public health concern [2]. Indeed, even low doses of Salmonella can cause a wide range of human and animal diseases [3]. The worldwide annual cost of medical treatment for Salmonella infections is about $\$ 11.4$ billion [4]. Consumption of the Salmonella pathogen via contaminated food or water causes most human infections [5]; it is estimated that 95\% of Salmonella infections are due to the consumption of contaminated foodstuffs [6]. Salmonella is most common in meat, processed meats, processed foods containing meat, eggs, and foods contaminated during processing [7]. Salmonella outbreaks following the consumption of chicken 
eggs contaminated with Salmonella enterica are relatively common $[8,9]$. Therefore, the rapid and accurate detection of Salmonella infections in chickens is of critical importance to animal husbandry, food safety, and human health.

The rapid detection method, which combines a polymerase chain reaction (PCR), a quantitative real-time PCR (qPCR), and an enzyme-linked immunosorbent assay (ELISA), is gradually becoming more widely used for the differential diagnosis of Salmonella and other foodborne pathogens [10, 11]. However, this method also has some disadvantages. For example, PCR and qPCR analyses will only detect pathogens above a certain concentration; these methods also cannot detect whether or not the bacteria was alive at the time of the analysis [11]. ELISAs require expensive instruments, and ELISA results are both unstable and highly influenced by the technique of the experimenter, therefore limiting the wider application of this method [12].

Several additional detection methods have been used for the detection of Salmonella, including gene chips, PCRpyrosequencing, pulsed-field gel electrophoresis (PFGE), ribotyping, intergenic sequence (IGS) typing, matrixassociated laser desorption ionization-time of flight mass spectrometry (MALDI-TOF MS), and chemiluminescence $[13,14]$. Unfortunately, these techniques require access to expensive laboratory instruments and specialized personnel; most also require large sample sizes. These methods are often time-consuming, labor-intensive, and complicated [15], making such tests difficult to popularize and promote in the field. Therefore, the development of new, userfriendly tests for Salmonella and other bacterial food pathogens is of great practical importance to public health and veterinary medicine.

In 2000, Notomi et al. [16] developed the easy and LAMP uses 4-6 specially designed primers and a strand-displacing Bst DNA polymerase to quickly perform isothermal amplification of target DNA [17] within one hour. The advantages of LAMP include high specificity, high sensitivity, and simple equipment requirements. The products of LAMP amplification are usually detected with gel electrophoresis, followed by either staining with ethidium bromide (EB) or the addition of calcein; contamination of the amplification product could produce false positives [18]. Unfortunately, these shortcomings reduce the practicality of the LAMP technique in the field.

Recent studies have shown that LAMP-LFD (lateral flow dipstick) is based on LAMP amplification principles, but it uses a test strip to display the results [19]. That is, LAMPLFD uses a biotin-labeled LAMP product hybridized with a digoxin-labeled DNA probe and complexed with a gold- labeled anti-digoxin antibody [20]. This hybridization product is trapped by a biotin ligand and bound to a lateral flow test strip, which forms an immune complex. Nonhybridized digoxin-labeled probes pass through the test line and bind to the goat anti-mouse immunoglobulin G (IgG) antibody control line [21]. The use of digoxin-labeled probes increases the detection specificity and sensitivity, reduces the number of false positives caused by nonspecific amplification, and ensures the accuracy of the results [22]. LAMP-LFD takes 10-15 min compared to 35$50 \mathrm{~min}$ required for gel electrophoresis [23]. This method also reduces the dependence on equipment and avoids the use of the carcinogen EB. Although LAMP-LFD detection methods have been successfully developed for a variety of pathogenic microorganisms [23-26], no LAMP-LFD method is yet available for the detection of Salmonella.

Here, we developed a novel LAMP-LFD method to rapidly detect Salmonella by targeting the invA gene. We evaluated the sensitivity, specificity, and reproducibility of our LAMP-LFD assay using pure Salmonella cultures, artificially contaminated feed, and clinical samples. Our LAMP-LFD assay is a reliable and effective diagnostic tool for the detection of avian salmonellosis in farm-based laboratories.

\section{Materials and Methods}

\section{Reagents and Materials}

We purchased a bacterial genome DNA extraction Kit, $10 \times \mathrm{PCR}$ buffer, and dNTP mix from Sangon Biotech Co., Ltd. (China). We bought Bst 2.0 DNA polymerase large fragment (M0538) from New England Biolabs, Ltd. (China). We obtained buffered peptone water (BPW) and Rappaport Vassiliadis Salmonella Enrichment Broth (RV) from Hopebio-Technology Co. (Qingdao, China). The LFD was provided by the Nucleic Acids Labeling and Detecting Lab, Key Laboratory of Ministry of Education with Provincial Co-Construction of Local and Ethnic High Incidence in Xinjiang (Shihezi, China). We purchased calcein, betaine, and $\mathrm{MgSO}_{4}$ from Sigma (USA).

\section{Bacterial Strains and Samples}

All strains of Salmonella and non-Salmonella bacteria used in this study were from stocks maintained at the Laboratory of Animal Zoonosis at Shihezi University (China; Table 1). We used S. enterica subsp. enterica serovar Pullorum (hereafter referred to as $S$. Pullorum) to test the specificity and sensitivity of our LAMPLFD assay, but all Salmonella species were used for the feedcontamination experiments. We bought feed and chicken eggshells from a farm in Shihezi, Xinjiang, China. We confirmed that the feed and eggshells were not contaminated with Salmonella using the culture method. We collected 350 anal swabs from 
Table 1. Serovars of Salmonella enterica subsp. enterica and other pathogenic bacterial species used in this study.

\begin{tabular}{|c|c|c|c|c|}
\hline Classification & Bacteria & Strains & Source & $\begin{array}{l}\text { Location of } \\
\text { separation }\end{array}$ \\
\hline \multirow[t]{7}{*}{ Target bacterial species } & Salmonella enterica subsp. enterica serovars & & & \\
\hline & Pullorum & $\mathrm{CVCC}^{\mathrm{a}} 530$ & $\mathrm{CVCC}^{\mathrm{a}}$ & USA \\
\hline & Pullorum & CVCC $^{a} 1791$ & $\mathrm{CVCC}^{\mathrm{a}}$ & Jiangsu, China \\
\hline & Typhimurium & $\mathrm{CVCC}^{\mathrm{a}} 542$ & $\mathrm{CVCC}^{\mathrm{a}}$ & Zhejiang, China \\
\hline & Enteritidis & CVCC $^{a} 3378$ & $\mathrm{CVCC}^{\mathrm{a}}$ & Beijing, China \\
\hline & Gallinarum & $\mathrm{CICC}^{\mathrm{b}} 21510$ & $\mathrm{CICC}^{\mathrm{b}}$ & Czech Republic \\
\hline & Pullorum & CVCC $^{a} 1802$ & $\mathrm{CVCC}^{\mathrm{a}}$ & Jiangsu, China \\
\hline \multirow{6}{*}{$\begin{array}{l}\text { Negative control } \\
\text { bacterial species }\end{array}$} & Pasteurella multocida & Serotype 5 & Isolated from raw chicken & \\
\hline & Escherichia coli & EC-xj 01 & Isolated from raw chicken & Xinjiang, China \\
\hline & Staphylococcus aureus & CVCC $^{a} 1885$ & $\mathrm{CVCC}^{\mathrm{a}}$ & Beijing, China \\
\hline & Avian aspergillus & CVCC $^{a} 3596$ & $\mathrm{CVCC}^{\mathrm{a}}$ & \\
\hline & Pseudomonas aeruginosa & & Isolated from raw chicken & \\
\hline & Haemophilus paragallinarum & Type A & Isolated from raw chicken & \\
\hline
\end{tabular}

${ }^{\mathrm{a}} \mathrm{CVCC}$, China Veterinary Culture Collection Center.

${ }^{\mathrm{b}} \mathrm{CICC}$, China Center of Industrial Culture Collection.

chickens on several large chicken farms around Urumqi, Xinjiang, China. All of the strains and specimens were stored at $-80^{\circ} \mathrm{C}$.

\section{Bacterial Culture and DNA Extraction}

All of the bacterial strains were cultured on common ordinary agar (Salmonella, Escherichia coli, Staphylococcus aureus, and Pseudomonas aeruginosa), potato dextrose agar (avian Aspergillus), or blood agar (Pasteurella multocida and Haemophilus paragallinarum) at $37^{\circ} \mathrm{C}$ for $20-48 \mathrm{~h}$. Haemophilus influenzae were grown under facultative anaerobic conditions $\left(10 \% \mathrm{CO}_{2}\right)$. We used the plate- colony counting method to determine the concentration of each culture. We used 10-fold serial dilutions with phosphate buffered solution (PBS) to dilute all of the bacterial cultures to approximately $10^{1}-10^{8} \mathrm{CFU} / \mathrm{ml}$. DNA was extracted from $1 \mathrm{ml}$ of diluted bacterial culture using the Bacterial Genome DNA Extraction Kit following the manufacturer's instructions. DNA concentration and quality were verified using UV spectrophotometric analysis at $\mathrm{A}_{260 \mathrm{~nm}}$ and $\mathrm{A}_{280 \mathrm{~nm}}$. Salmonella DNA was used in the LAMP reactions directly.

Table 2. Specific primers and probes designed for Salmonella invA detection.

\begin{tabular}{|c|c|c|c|}
\hline Primer name & Type & Sequences $\left(5^{\prime} \rightarrow 3^{\prime}\right)$ & Length (bases) \\
\hline \multicolumn{4}{|l|}{ PCR } \\
\hline invAF & Forward primer & AAAAGAAGGGTCGTCGTTAGG & 21 \\
\hline invAR & Backward primer & CCACTCGCATCAAATCAAAA & 20 \\
\hline \multicolumn{4}{|l|}{ LAMP } \\
\hline invAF3 & Forward-outer primer & AGCTGTTGAACAACCCATTTG & 20 \\
\hline $\operatorname{invAB3}$ & Backward-outer primer & TCGGCACAAGTAATATCAAC & 19 \\
\hline invAFIP ${ }^{a}$ & Forward-inner primer & CTCAATACTGAGCGGCTGCTC & 45 \\
\hline$(\mathrm{F} 1 \mathrm{c}+\mathrm{tttt}+\mathrm{F} 2)$ & & tttGTTGTTACGGCTATTTTGA & \\
\hline invABIP & Backward-inner primer & GGTGGTTTTAAGCGTACT & 43 \\
\hline$(\mathrm{B} 1 \mathrm{c}+\mathrm{tttt}+\mathrm{B} 2)$ & & ttttGTCTCTGTAGAGACTTTAT & \\
\hline invALP & Loop-backward primer & TCCGTGAAGCAAAACGTAGCGCCG & 24 \\
\hline \multicolumn{4}{|c|}{ Probe for LAMP-LFD } \\
\hline invA-HP ${ }^{b}$ & Hybridization probe & CGGTGGTTTTAAGCGTACTC & 20 \\
\hline
\end{tabular}

${ }^{\mathrm{a}} 5$ '-Labeled with biotin when used in the LAMP-LFD assay.

${ }^{\mathrm{b}} 5$ '- Labeled with digoxin when used in the LAMP-LFD assay. 


\section{LAMP Primers and Probe}

To ensure assay specificity, five primers and a probe were designed to identify eight regions of the target gene (invA). All of the $i n v A$ sequences were aligned with DNAMAN 4.0 [22], and the conserved regions were used for analysis across the Salmonella species. We designed LAMP primers using PrimerExplorer v3 (http://primerexplorer.jp; [27]), based on the invA genes in the previously published S. enterica genome (GenBank Accession No: NC003197.1). We designed two outer primers (F3 and B3), two inner primers (FIP and BIP), a loop primer (LP), and a probe (HP). FIP was labeled with biotin at the $5^{\prime}$ end, and HP was labeled with digoxin at the $5^{\prime}$ end (Table 2). All of the primers and the probe were synthesized and labeled by Sangon Biotech (China).

\section{PCR Assay}

We made up specific PCR mixtures $(50 \mu \mathrm{l})$ for each of the Salmonella strains. PCR mixtures contained $20 \mu \mathrm{M}$ invAF, $20 \mu \mathrm{M}$ invAR, 5 U ExTaq DNA polymerase, $5 \mu 110 \times$ PCR buffer, $2.5 \mathrm{mM}$ dNTPs, and $1 \mu \mathrm{l}$ DNA from the given strain. All of the reaction cycles were $95^{\circ} \mathrm{C}$ for $5 \mathrm{~min} ; 30$ cycles of $95^{\circ} \mathrm{C}$ for $40 \mathrm{sec}, 59^{\circ} \mathrm{C}$ for $30 \mathrm{sec}$, and $72^{\circ} \mathrm{C}$ for $20 \mathrm{sec}$; and a final extension of $72^{\circ} \mathrm{C}$ for $10 \mathrm{~min}$. After PCR amplification, we analyzed $5 \mu \mathrm{l}$ of the PCR product with $2.5 \%$ agarose gel electrophoresis (AGE) using $0.6 \mu \mathrm{g} / \mathrm{ml}$ EB. The target amplicon was a 278-bp fragment of the Salmonella invA gene. All of the experiments were repeated at least three times.

\section{LAMP Assay}

Following a previous study [25], LAMP was performed in a $25-\mu$ l reaction mixture containing $1 \mu \mathrm{l}$ of the inner primers $(20 \mathrm{~mol} / \mathrm{l})$, $1 \mu \mathrm{l}$ of the outer primers $(10 \mathrm{~mol} / \mathrm{l}), 1 \mu \mathrm{l}$ of the LP primer $(15 \mathrm{~mol} / \mathrm{l})$, $2.5 \mu \mathrm{l} 10 \times$ ThermoPol buffer, $3.5 \mu \mathrm{l}$ dNTPs, $2.5 \mu \mathrm{l}$ betaine $(10 \mathrm{~mol} / \mathrm{l})$,

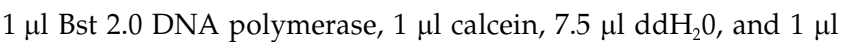
DNA template. We used the genome of $S$. Pullorum as a positive control $(8.9 \mathrm{ng} / \mu \mathrm{l})$, and the non-Salmonella genome as the negative control. Reaction mixtures were briefly centrifuged, then incubated in a $60^{\circ} \mathrm{C}$ water bath for $50 \mathrm{~min}$. We analyzed $5 \mu \mathrm{l}$ of the amplified product with 3\% AGE and the fluorescent dye method.

To determine the optimal LAMP conditions, we altered the ratio of the inner primer to the outer primer $(5: 1-2: 1)$, the concentration of dNTPs (0.1-1.4 mM), and the concentration of $\mathrm{MgSO}_{4}(1-8 \mathrm{mM})$. We also varied the amplification temperature $\left(54^{\circ} \mathrm{C}-64^{\circ} \mathrm{C}\right)$ and the amplification time $(20-60 \mathrm{~min})$.

\section{LFD Assay}

To detect the LAMP products with LFD, a gold-labeled antidigoxin antibody and an anti-biotin antibody were embedded in an LFD. After the LAMP reaction was complete, 20 pmol of the digoxin-labeled invA-HP probe was added to the reaction solution. The mixture was held at $60^{\circ} \mathrm{C}$ for $5 \mathrm{~min}$ and then allowed to hybridize with a digoxin-labeled oligonucleotide probe at $80^{\circ} \mathrm{C}$ for $5 \mathrm{~min}$. After hybridization, $5 \mu \mathrm{l}$ of the hybridized product was added to a clean tube containing $100 \mu \mathrm{l}$ LAMP reaction buffer. We

A

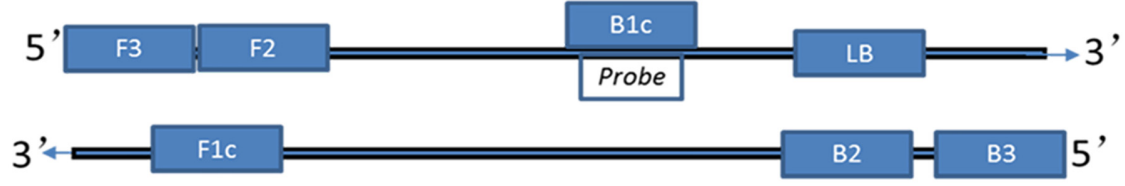

B

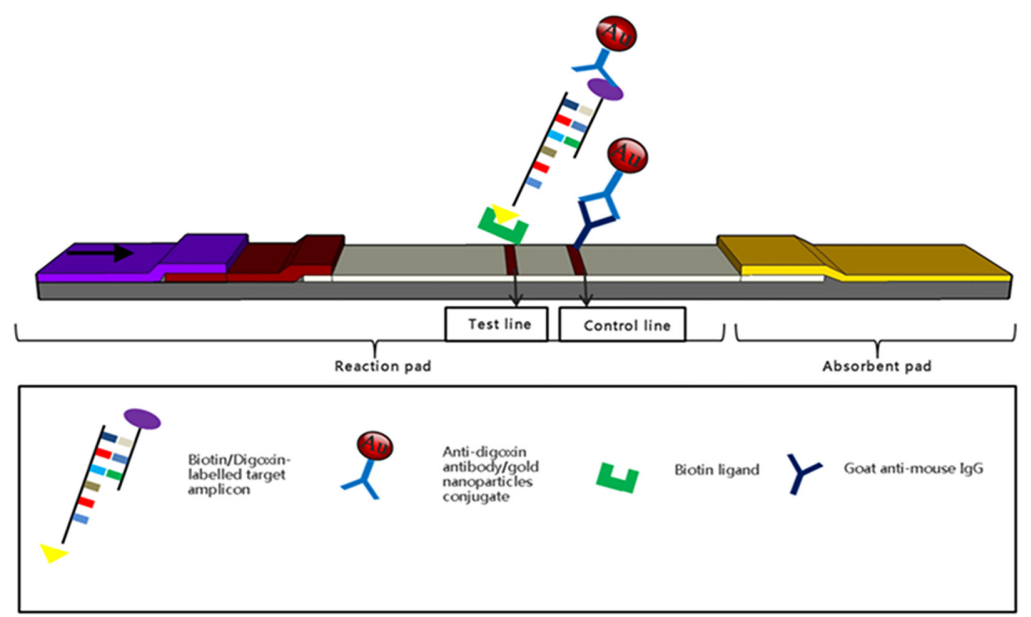

C

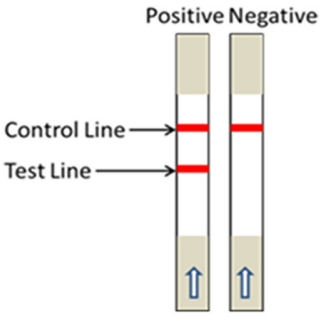

Fig. 1. Overview of the LAMP-LFD assay.

(A) The location of the primer pairs and probe, which were designed based on the conserved region of the Salmonella invA gene. (B) The triplelabeled product (biotinylated LAMP amplicon hybridized with the digoxin-labeled probe forming a complex with the gold-conjugated antidigoxin antibody) is bound by the biotin ligand embedded on the test line and/or with anti-mouse antibody embedded on the control line. (C) Bands at both the control and test lines are required for a positive result. A single band at the control line is interpreted as a negative result. 
then applied $80 \mu \mathrm{l}$ of the new mixture to the LFD strips with the sample pad. The hybridization results were visible to the naked eye within $5 \mathrm{~min}$. When two bands appeared on the LFD (at the test line and at the control line), it indicated a positive result. A sample producing a single band at the control line indicated a negative result (Fig. 1). If no band appeared at the control line, the test strip was considered to be invalid.

Specificity, Repeatability, and Sensitivity of LAMP-LFD Assay

To determine the specificity of the LAMP-LFD assay under optimized conditions, we extracted genomic DNA from six Salmonella species and several negative control species (Table 1) that potentially exist in chicken [28]. All of the bacterial strains were tested at $10^{4} \mathrm{CFU} / \mathrm{ml}$. To determine the reproducibility of the LAMP-LFD assays, five parallel samples of $S$. Pullorum at $89 \mathrm{pg} / \mu \mathrm{l}$ and $8.9 \mathrm{pg} / \mu \mathrm{l}$ were analyzed with LAMP and LAMPLFD. We added E. coli genomic DNA to the negative control instead of using a positive template. The LAMP reaction products were analyzed with $3 \%$ AGE and LFD. To determine the sensitivity of LAMP-LFD, we performed 10-fold serial dilutions of Salmonella DNA with PBS, diluting samples from $89 \mathrm{ng} / \mu \mathrm{l}$ to $8.9 \mathrm{fg} / \mu \mathrm{l}$. These serial dilutions were used as the DNA template $(1 \mu \mathrm{l})$ for the LAMP assays and PCR. The LAMP products were analyzed with $3 \%$ AGE and LFD. The PCR products were analyzed with $2.5 \%$ AGE.

\section{Detection of Salmonella in Feed Samples}

We analyzed two types of chicken feed: eggshells and feed. We tested for Salmonella using the conventional culture method. Negative samples were used to test the sensitivity of the LAMPLFD to artificial pollution. Test portions ( $25 \mathrm{~g})$ were inoculated with $225 \mathrm{ml}$ of the respective BPW. A similar sample, without added Salmonella, was used as the negative control. Samples were cultured at $37^{\circ} \mathrm{C}$ with $180 \mathrm{rpm} / \mathrm{min}$ shaking for $18-24 \mathrm{~h}$. We then added $10 \mathrm{ml}$ of the sample culture to $100 \mathrm{ml}$ of $\mathrm{RV}$ medium. This new mixture was cultured at $37^{\circ} \mathrm{C}$ with $180 \mathrm{rpm} / \mathrm{min}$ shaking for $24 \mathrm{~h}$. After culturing, the Salmonella concentration spiked, ranging from $10^{8}$ to $10^{4} \mathrm{CFU} / 25 \mathrm{~g}$ based on aerobic plate counts. We then centrifuged $1 \mathrm{ml}$ of the final culture mix in sterile test tubes at $900 \times g$ for $3 \mathrm{~min}$ to remove the large particles. We used the Bacterial Genome DNA Extraction kit to extract DNA for use as a detection template (following Wang [29]). We used $2 \mu \mathrm{l}$ of this template for LAMP-LFD, conventional LAMP, and PCR assays; these assays were repeated three times each.

\section{Evaluation of the LAMP-LFD Assay with Clinical Samples}

To evaluate the performance of the LAMP-LFD assay, we established a reference standard that combined the results of the GB/T4789.4-2008 method and PCR. A sample was considered to be positive when either the GB/T4789.4-2008 method or PCR showed positive results. Our LAMP-LFD assay was conducted on the chicken anal swabs that we collected. We compared our LAMP-LFD results with those of the conventional PCR assay. The
A

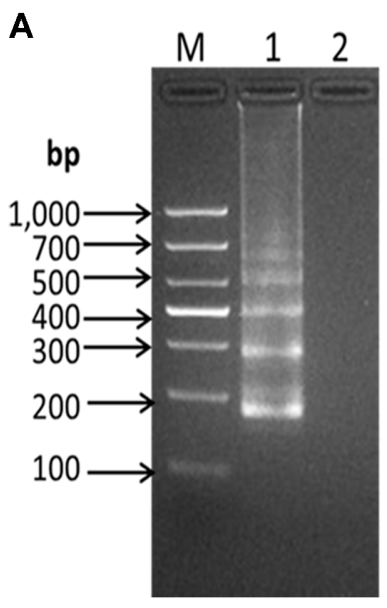

B

C

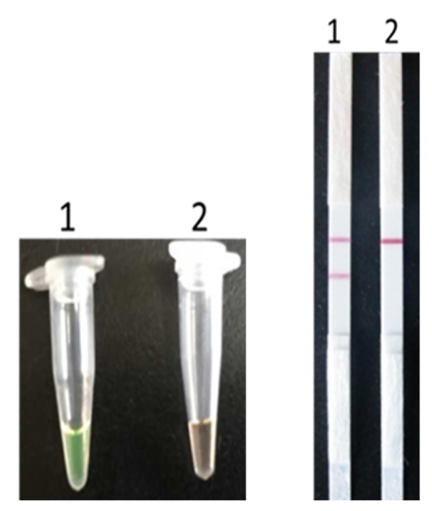

Fig. 2. Verification of the Salmonella LAMP-LFD assays.

(A) Agarose gel electrophoresis of LAMP products. Lane M: DNA markers; Lane 1; LAMP products; and Lane 2; negative control. (B) Visual inspection of LAMP products using calcein. (C) The LAMPLFD assay.

PCR products were analyzed with 2.5\% AGE, while the LAMP reaction products were analyzed with $3 \% \mathrm{AGE}$ and LFD.

\section{Results}

\section{Salmonella Detection with LAMP-LFD}

To develop the LAMP-LFD method, we used the $S$. Pullorum genomic DNA as the target template. Our electrophoresis results indicated that templates positive for Salmonella had bands with a ladder-like pattern, while negative control templates did not have any bands (Fig. 2A). Our analysis of LAMP with calcein indicated that templates positive for Salmonella fluoresced green, while blank control templates fluoresced orange (Fig. 2B). Finally, our LAMP-LFD analysis indicated that templates positive for Salmonella had red bands in both the detection and the control areas; negative control templates had only a single red band in the control space (Fig. 2C).

\section{Optimization of Salmonella LAMP}

We measured the brightness and consistency of the ladder-like LAMP product bands obtained via electrophoresis, as well as the gray values, with Image $\mathrm{Lab}^{\mathrm{TM}} 2.0$ software (Bio-Rad Laboratories, USA), following the manufacturer's instructions. To determine the optimal amplification conditions after experimentation, we found that an inner primer to outer primer ratio of 3:1 resulted in maximum amplification of the LAMP product (Fig. S1A). The optimum concentrations of dNTPs and $\mathrm{Mg}^{2+}$ in the master mix were 
$0.5 \mathrm{mM}$ (Fig. S1B) and $4 \mathrm{mM}$ (Fig. S1C), respectively. Thus, our optimal Salmonella LAMP master mix contained $2.5 \mu \mathrm{l}$ $10 \times$ ThermoPol buffer, $4 \mathrm{mM} \mathrm{MgS0} 0_{4}, 0.8 \mathrm{mM}$ dNTPs, $1 \mu \mathrm{l}$ calcein, $1.5 \mathrm{mM}$ betaine, $0.7 \mu \mathrm{M}$ each of outer primer (F3 and B3), $2.1 \mu \mathrm{M}$ each of inner primer (FIP and BIP), $0.8 \mu \mathrm{M}$ LP primer, and $1 \mu \mathrm{l}$ of target DNA.

To optimize the amplification temperature, we maintained our optimal LAMP reaction mixture with $1 \mu \mathrm{S}$. Pullorum DNA $(58 \mathrm{ng} / \mu \mathrm{l})$ template under isothermal conditions $\left(54^{\circ} \mathrm{C}-64^{\circ} \mathrm{C}\right)$ for $50 \mathrm{~min}$. After LAMP amplification at $60^{\circ} \mathrm{C}$, four bright bands were visible; these bands were brighter than those observed after amplification at other temperatures (Fig. S1D). We thus considered $60^{\circ} \mathrm{C}$ the optimal temperature for the Salmonella LAMP assay.

Next, to determine the optimal reaction time, we held our optimal LAMP reaction mixture with $1 \mu \mathrm{L} S$. Pullorum positive control template at $60^{\circ} \mathrm{C}$ for $20-60 \mathrm{~min}$. After $20 \mathrm{~min}$, LAMP amplification products were detectable by
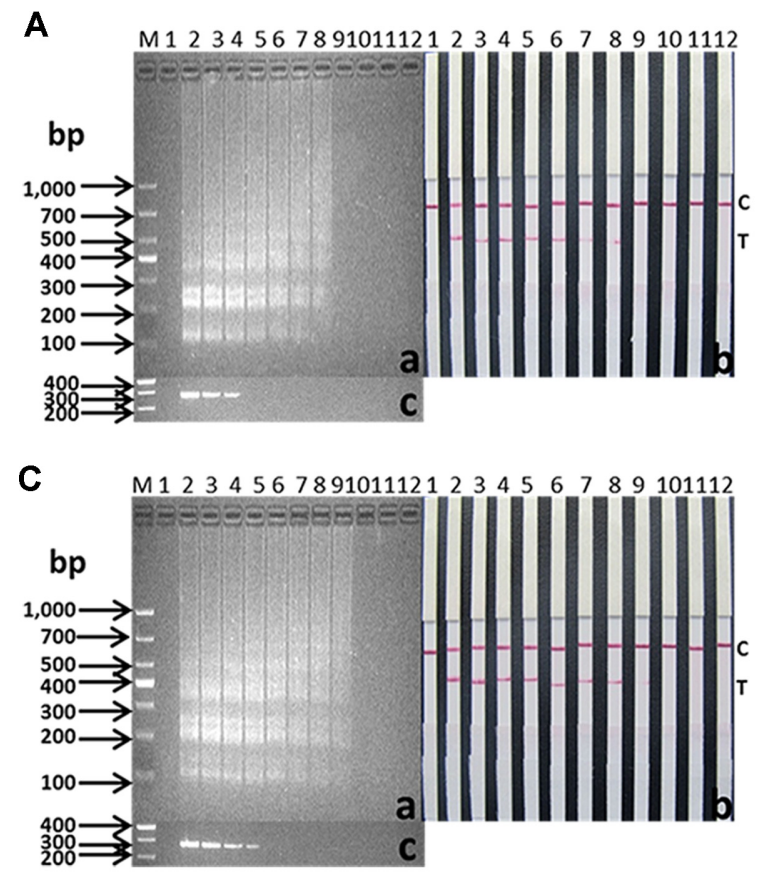

electrophoresis. After $40 \mathrm{~min}$, the amplification product was saturated (Fig. S1E). We thus considered $40 \mathrm{~min}$ the optimal duration for the Salmonella LAMP assay.

\section{LAMP-LFD Specificity, Repeatability and Sensitivity}

As for specificity, all of the six Salmonella species tested positive with a clear visible test line on the strip, while all non-Salmonella (negative control) species tested negative (Figs. S2A and S2B). Thus, the specificity of LAMP-LFD was sufficient. The repeatability of the LAMP-LFD was evaluated through comparison of the results obtained from five parallel samples. For $89 \mathrm{pg} / \mu \mathrm{l}$ and $8.9 \mathrm{pg} / \mu \mathrm{l}$ synthetic DNA, the five parallel samples obtained test results. For $8.9 \mathrm{pg} / \mu \mathrm{l}$ synthetic DNA, five out of five test samples had identical results, which indicated that the LAMP-LFD was reproducible. The sensitivities of the LAMP, LAMP-LFD, and PCR assays were also tested using a 10-fold dilution of S. Pullorum DNA. The LAMP plus gel electrophoresis
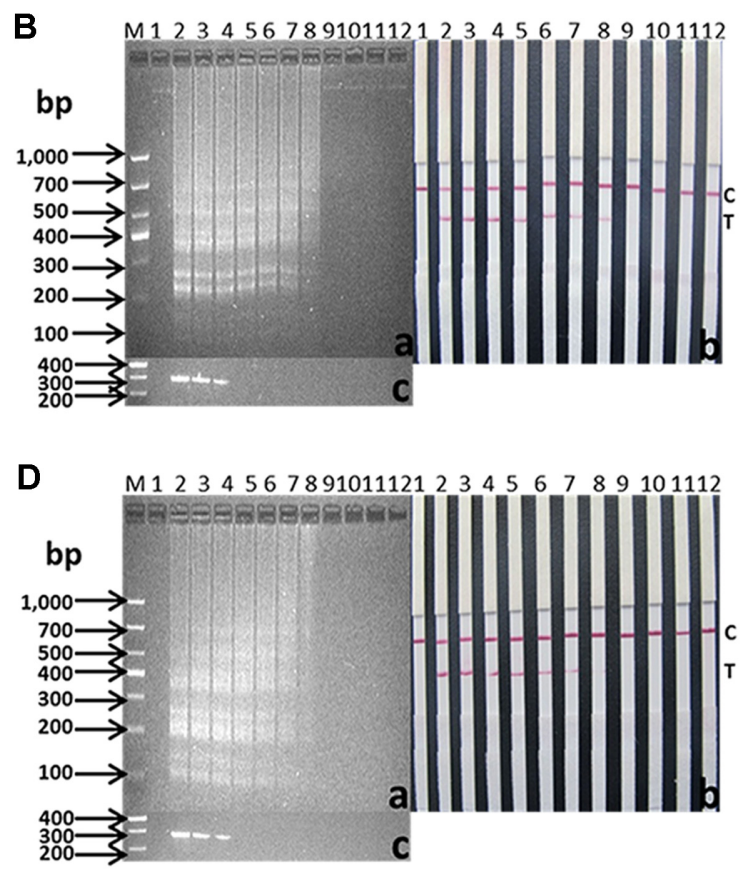

Fig. 3. Sensitivity of (a) LAMP, (b) LAMP-LFD, and (c) conventional PCR in the eggshells artificially contaminated with various serovars of Salmonella enterica subsp. enterica.

Assay evaluation in the eggshells artificially contaminated with (A) S. enterica subsp. enterica Pullorum, (B) S. enterica subsp. enterica Enteritidis, and (D) S. enterica subsp. enterica Typhimurium. Lane M: DNA markers; Lane 1: negative control (no template); Lane 2: $1.0 \times 10^{6} \mathrm{CFU} / 25 \mathrm{~g}$; Lane 3: $9.0 \times 10^{5} \mathrm{CFU} / 25 \mathrm{~g}$; Lane 4: $8.0 \times 10^{5} \mathrm{CFU} / 25 \mathrm{~g}$; Lane 5: $7.0 \times 10^{5} \mathrm{CFU} / 25 \mathrm{~g}$; Lane 6: $6.0 \times 10^{5} \mathrm{CFU} / 25 \mathrm{~g}$; Lane 7: $9.0 \times 10^{3} \mathrm{CFU} / 25 \mathrm{~g}$; Lane 8: $8.0 \times 10^{3}$ $\mathrm{CFU} / 25 \mathrm{~g}$; Lane 9: $7.0 \times 10^{3} \mathrm{CFU} / 25 \mathrm{~g}$; Lane 10: $6.0 \times 10^{3} \mathrm{CFU} / 25 \mathrm{~g}$; Lane 11: $5.0 \times 10^{3} \mathrm{CFU} / 25 \mathrm{~g}$; and Lane $12: 4.0 \times 10^{3} \mathrm{CFU} / 25 \mathrm{~g}$. Assay evaluation in the eggshells artificially contaminated with (C) S. enterica subsp. enterica Gallinarum. Lane M: DNA markers; Lane 1: negative control (no template); Lane 2: $1.0 \times 10^{7} \mathrm{CFU} / 25 \mathrm{~g}$; Lane 3: $9.0 \times 10^{6} \mathrm{CFU} / 25 \mathrm{~g}$; Lane 4: $8.0 \times 10^{6} \mathrm{CFU} / 25 \mathrm{~g}$; Lane 5: $7.0 \times 10^{6} \mathrm{CFU} / 25 \mathrm{~g}$; Lane 6: $7.0 \times 10^{5} \mathrm{CFU} / 25$ g; Lane 7: $9.0 \times 10^{4} \mathrm{CFU} / 25 \mathrm{~g}$; Lane 8: $8.0 \times 10^{4} \mathrm{CFU} / 25 \mathrm{~g}$; Lane 9: $7.0 \times 10^{4} \mathrm{CFU} / 25 \mathrm{~g}$; Lane 10: $6.0 \times 10^{4} \mathrm{CFU} / 25 \mathrm{~g}$; Lane $11: 5.0 \times 10^{4} \mathrm{CFU} / 25 \mathrm{~g}$; and Lane 12: $4.0 \times 10^{4} \mathrm{CFU} / 25 \mathrm{~g}$. 
method (Fig. S3A), the calcein visual LAMP method (Fig. S3B), and the LAMP-LFD method (Fig. S3C) had similar degrees of sensitivity, detecting concentrations of genomic DNA as low as $89 \mathrm{fg} / \mu \mathrm{l}$. The detection limit of conventional PCR was $89 \mathrm{pg} / \mu \mathrm{l}$ of genomic DNA (Fig. S3D). Therefore, LAMP and LAMP-LFD detected concentrations 1,000 times lower than conventional PCR. Therefore, our Salmonella LAMP-LFD assay was suitable for Salmonella detection.

\section{Detection of Salmonella in Spiked Feed Samples}

In the artificially contaminated eggshells, the detection limit of LAMP-LFD and LAMP was approximately $8 \times 10^{3}$ $\mathrm{CFU} / 25 \mathrm{~g}$, with the exception of $S$. enterica subsp. enterica serovar Gallinarum (hereafter referred to as $S$. Gallinarum),
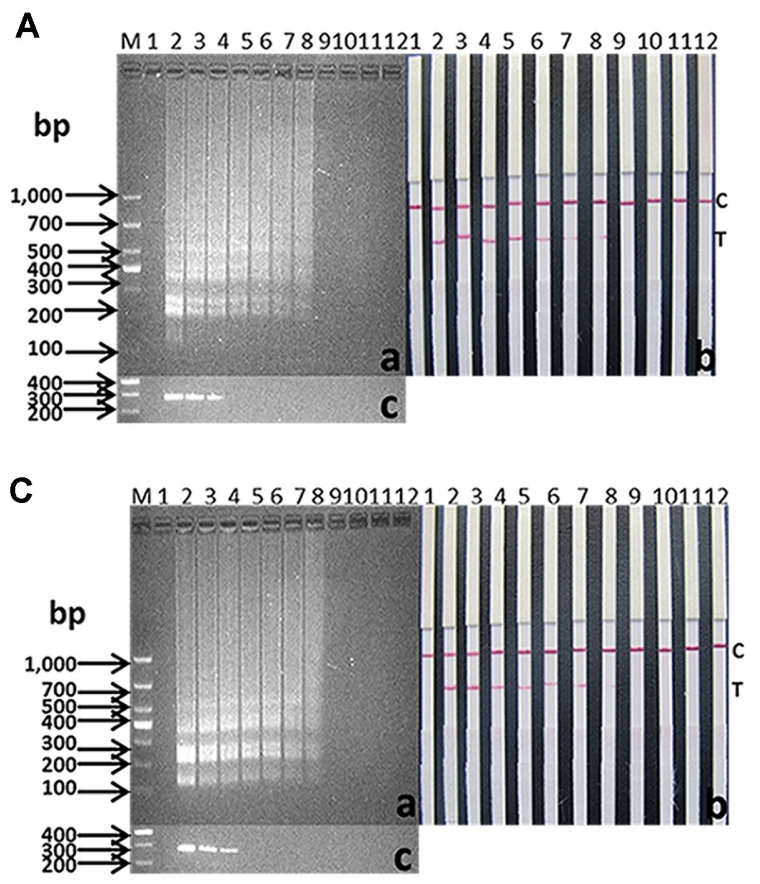

for which the detection limit was $10^{5} \mathrm{CFU} / 25 \mathrm{~g}$ (Figs. 3A3D). Across the three repeats, LAMP (once) and LAMPLFD (twice) returned a positive band at a Salmonella concentration of $8 \times 10^{3} \mathrm{CFU} / 25 \mathrm{~g}$. In contrast, PCR detected some species of Salmonella in some repeats at concentrations of $7.0 \times 10^{5} \mathrm{CFU} / 25 \mathrm{~g}$ (S. Pullorum, S. enterica subsp. enterica serovar Enteritidis, and S. enterica subsp. enterica serovar Typhimurium), but only detected $S$. Gallinarum at concentrations greater than $10^{6} \mathrm{CFU} / 25 \mathrm{~g}$. In the artificially contaminated chicken feed, LAMP-LFD and LAMP detected all of the species of Salmonella at concentrations of $8.0 \times 10^{4} \mathrm{CFU} / 25 \mathrm{~g}$. PCR detected all of the species, except for $S$. Pullorum, at $8.0 \times 10^{4} \mathrm{CFU} / 25 \mathrm{~g}$; $S$. Pullorum was detected by PCR at $8.0 \times 10^{6} \mathrm{CFU} / 25 \mathrm{~g}$ (Figs. 4A-4D).
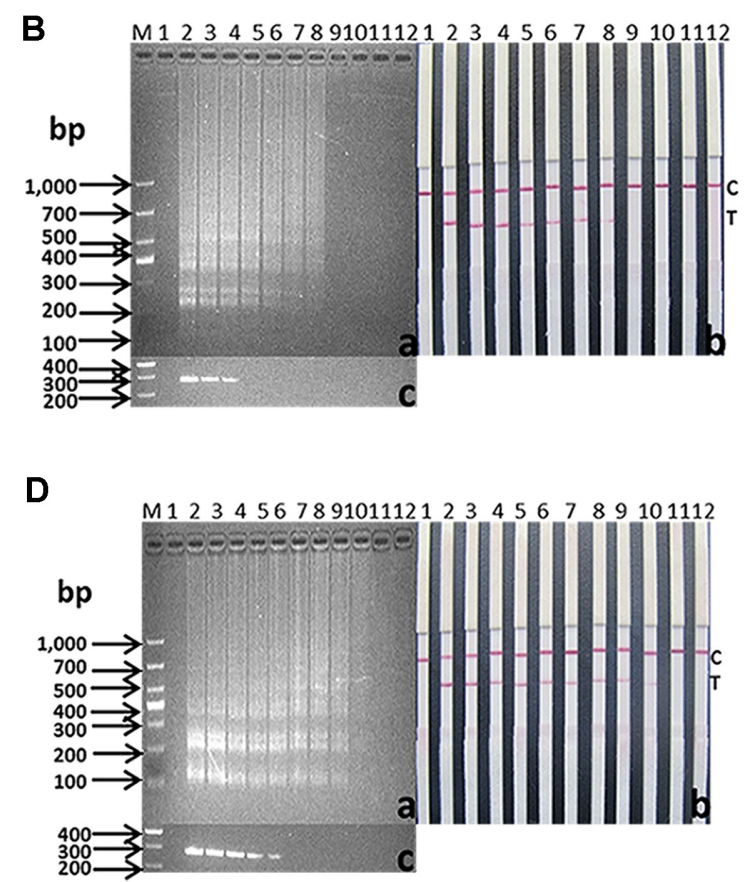

Fig. 4. Sensitivity of (a) LAMP, (b) LAMP-LFD, and (c) conventional PCR in the chicken feed artificially contaminated with various serovars of Salmonella enterica subsp. enterica.

Assay evaluation in the chicken feed artificially contaminated with (A) S. enterica subsp. enterica Pullorum. Lane M: DNA markers; Lane 1: negative control (no template); Lane 2: $1.0 \times 10^{8} \mathrm{CFU} / 25 \mathrm{~g}$; Lane 3: $9.0 \times 10^{7} \mathrm{CFU} / 25 \mathrm{~g}$; Lane 4: $8.0 \times 10^{7} \mathrm{CFU} / 25 \mathrm{~g}$; Lane 5: 7.0 $\times 10^{7} \mathrm{CFU} / 25 \mathrm{~g}$; Lane 6: $6.0 \times 10^{7} \mathrm{CFU} / 25 \mathrm{~g}$; Lane 7: $9.0 \times 10^{4} \mathrm{CFU} / 25 \mathrm{~g}$; Lane 8: $8.0 \times 10^{4} \mathrm{CFU} / 25 \mathrm{~g}$; Lane 9: $7.0 \times 10^{4} \mathrm{CFU} / 25 \mathrm{~g}$; Lane 10: $6.0 \times 10^{4} \mathrm{CFU} / 25 \mathrm{~g}$; Lane 11 : $5.0 \times 10^{4} \mathrm{CFU} / 25 \mathrm{~g}$; Lane 12: $4.0 \times 10^{4} \mathrm{CFU} / 25 \mathrm{~g}$. Assay evaluation in the chicken feed artificially contaminated with (B) S. enterica subsp. enterica Enteritidis and (C) S. enterica subsp. enterica Gallinarum. Lane M: DNA markers; Lane 1: negative control (no template); Lane 2: $1.0 \times 10^{7} \mathrm{CFU} / 25$ g; Lane 3: $9.0 \times 10^{6} \mathrm{CFU} / 25 \mathrm{~g}$; Lane 4: $8.0 \times 10^{6} \mathrm{CFU} / 25 \mathrm{~g}$; Lane 5: $7.0 \times 10^{6} \mathrm{CFU} / 25 \mathrm{~g}$; Lane 6: $6.0 \times 10^{6} \mathrm{CFU} / 25 \mathrm{~g}$; Lane 7: $9.0 \times 10^{4} \mathrm{CFU} / 25 \mathrm{~g}$; Lane 8: $8.0 \times 10^{4} \mathrm{CFU} / 25 \mathrm{~g}$; Lane 9: $7.0 \times 10^{4} \mathrm{CFU} / 25 \mathrm{~g}$; Lane 10: $6.0 \times 10^{4} \mathrm{CFU} / 25 \mathrm{~g}$; Lane 11: $5.0 \times 10^{4} \mathrm{CFU} / 25 \mathrm{~g}$; and Lane $12: 4.0 \times 10^{4} \mathrm{CFU} / 25 \mathrm{~g}$. Assay evaluation in the chicken feed artificially contaminated with (D) S. enterica subsp. enterica Typhimurium. Lane M: DNA markers; Lane 1: negative control (no template); Lane 2: $1.0 \times 10^{7} \mathrm{CFU} / 25 \mathrm{~g}$; Lane 3: $9.0 \times 10^{6} \mathrm{CFU} / 25 \mathrm{~g}$; Lane 4: 8.0 × 10 $0^{6} \mathrm{CFU} / 25 \mathrm{~g}$; Lane 5: $7.0 \times 10^{6} \mathrm{CFU} / 25 \mathrm{~g}$; Lane 6: 6.0 $\times$ $10^{6} \mathrm{CFU} / 25 \mathrm{~g}$; Lane 7: $5.0 \times 10^{6} \mathrm{CFU} / 25 \mathrm{~g}$; Lane 8: $8.0 \times 10^{5} \mathrm{CFU} / 25 \mathrm{~g}$; Lane 9: $7.0 \times 10^{5} \mathrm{CFU} / 25 \mathrm{~g}$; Lane 10: $6.0 \times 10^{5} \mathrm{CFU} / 25 \mathrm{~g}$; Lane $11: 5.0 \times 10^{5}$ $\mathrm{CFU} / 25 \mathrm{~g}$; and Lane 12: $4.0 \times 10^{5} \mathrm{CFU} / 25 \mathrm{~g}$. 


\section{Diagnostic Application of LAMP-LFD}

Of the 350 clinical samples (chicken anal swabs), our LAMP-LFD assay identified 45 as positive for Salmonella, with a positive rate of $12.86 \%$; the parallel PCR identified 42 as positive, with a positive rate of $12.00 \%$. LAMP-LFD was $100 \%$ consistent with the results of the Chinese National Standard method, while PCR was $93.31 \%$ consistent. This indicated that our LAMP-LFD assay would be appropriate for use in the field.

\section{Discussion}

Salmonella is a common pathogen that often causes bacterial food poisoning [30]. This bacteria therefore not only damages the livestock industry but also poses a serious threat to human health and safety. Although avian salmonellosis severely impacts the Chinese poultry industry, few effective vaccines and drugs are available to prevent and cure this disease. Methods for the early detection of Salmonella contamination are needed for the effective prevention and monitoring of this disease.

Sensitivity, convenience, practicality, efficiency and cost are the main factors that determine whether a pathogen detection method will be useful in the field [31]. Accurate diagnoses with the traditional microbial detection methods take at least one week, and typically require enrichment culture [32]. In contrast, we have shown that our LAMPLFD assay is a fast, simple, effective, specific and sensitive technique for identifying Salmonella contamination. Although LAMP-LFD was based on the traditional LAMP method, LAMP-LFD has several advantages over LAMP. For example, the probe we used increased the detection specificity of LAMP-LFD, while the immunochromatographic strip was fast and convenient. The sensitivity of LAMPLFD to Salmonella nucleic acids is consistent with that of LAMP, indicating that LAMP-LFD is suitable for use with clinical samples. LAMP-LFD returned LAMP amplification results with detection that was sensitive to $89 \mathrm{fg} / \mu \mathrm{l}$ of Salmonella gDNA within $5 \mathrm{~min}$. Indeed, LAMP-LFD was 1,000 times more sensitive than conventional PCR, and the detection limit of LAMP-LFD was equivalent to that of LAMP-calcein gel electrophoresis. We validated the LAMP-LFD method using 350 clinical samples from poultry farms. LAMP-LFD identified $12.86 \%$ of the samples as positive for Salmonella, consistent with the results of the Chinese National Standard method. LAMP-LFD was slightly less sensitive to Salmonella DNA in artificially contaminated feed samples, suggesting that the type and origin of Salmonella contamination directly affects LAMP-
LFD sensitivity. LAMP-LFD assays accurately detected Salmonella contamination as low as $8 \times 10^{3} \mathrm{CFU} / 25 \mathrm{~g}$ across all feed types. This is consistent with the single previous study of LAMP sensitivity to Salmonella DNA in artificially contaminated feed samples [33]. It is worth nothing that the sensitivity of LAMP-LFD varied both when different serotypes of Salmonella contaminated otherwise identical feed samples and when different types of feed were infected with identical Salmonella serotypes (Fig. 3). This was consistent with a previous study, which suggested that invA gene polymorphisms in different Salmonella serovars might cause the observed differences in the samples [32].

Temperature strongly affected the sensitivity of our LAMP assay. The amplification temperature of LAMP using Bst DNA polymerase is typically $60^{\circ} \mathrm{C}-65^{\circ} \mathrm{C}$ [16], but our LAMP assay was most sensitive at $60^{\circ} \mathrm{C}$. When the amplification temperature was increased, the assay sensitivity decreased. The activity of Bst DNA polymerase depends on $\mathrm{Mg}^{2+}$ concentration [34]. In our LAMP reaction, the final $\mathrm{Mg}^{2+}$ concentration was $4 \mathrm{mM}$, and the $\mathrm{Mg}^{2+}$ concentration for PCR was between $0.5 \mathrm{mmol} / 1$ and $2.5 \mathrm{mmol} / 1$ [35], indicating that high concentrations of $\mathrm{Mg}^{2+}$ improved assay sensitivity. Similarly, the Bst DNA polymerase used in the LAMP reaction had a higher inhibitor tolerance than of the Taq MasterMix used for PCR [36]. In addition, dNTP concentration is closely related to LAMP amplification efficiency [34]; the final dNTP concentration for PCR is typically between $50 \mu \mathrm{M}$ and $200 \mathrm{mM}$ [35]. Here, LAMP-LFD was most sensitive at $0.5 \mathrm{mM}$ dNTP; when the dNTP concentration was increased above $0.5 \mathrm{mM}$, assay sensitivity decreased. Thus, LAMP reaction conditions directly affected detection specificity and sensitivity of the LAMP-LFD method. It is therefore critical to optimize the LAMP reaction system to improve the efficacy of LAMP-LFD.

As there is a correlation between Salmonella contamination and the most serious food safety hazards, we focused on the S. enterica subsp. enterica serovars Pullorum, Gallinarum, Typhimurium, and Enteritidis. LFDs performed after the LAMP amplification of the invA gene in Salmonellacontaminated samples were positive, while LFDs performed after LAMP amplification of non-Salmonella strains were negative. Therefore, LAMP-LFD was sufficiently specific. Although the specificity and sensitivity of LAMP-LFD were high, our samples were obtained from only a few poultry farms in one area of China, and might not have accurately represented the known diversity of Salmonella serovars (> 2,500; [37]). Therefore, the popularity and reliability of this detection method must be confirmed in 
future studies, preferably encompassing samples from several areas. Sample sizes should also be increased.

LAMP analysis requires accurate primer design, a stable reaction system, and a sterile working area [38]. The selection of the target genes is the key to LAMP technology. To design our Salmonella LAMP assay, we first designed primers for the Salmonella invA gene based on a previously published Salmonella genome. The gene invA is highly conserved and found only in pathogenic Salmonella species. This gene is thus often used as a diagnostic marker to rapidly and accurately detect Salmonella contamination in food [39-41]. LAMP has been used worldwide to detect pathogenic microorganisms, clinically diagnose diseases, and determine embryo sex [42]. Thus, LAMP-LFD is potentially useful for the rapid, sensitive detection of Salmonella. Previous studies have shown that the sensitivity of PCR pathogen detection was affected by the presence of PCR inhibitors in the samples tested [43]. The development of PCR for rapid clinical diagnosis has also been hampered by a lack of adequate validation techniques [44]. LAMP results are easier to generate and interpret than those of qPCR or PCR [45]; LAMP is also approximately 2 times faster than qPCR [46]. More importantly, the LAMP-LFD procedure is simple: the entire reaction takes place at a constant temperature $\left(60^{\circ} \mathrm{C}\right)$ in a reasonable amount of time, rendering a thermocycler or qPCR system unnecessary. Furthermore, the results can be interpreted directly with the naked eye. The addition of primers in the LAMP method is controversial because specific staircase bands might also be produced without the use of external primers [47]. The loop primers in the LAMP method shorten the reaction time and increase the efficiency of amplification, possibly because ring primers hybridized with the stem loop structure, starting strand displacement DNA synthesis. At present, the use of the LAMP assay is widespread and increasing, but several problems and defects of this assay remain to be clarified [48]. For example, LAMP amplification can also occur with invariant DNA templates, but the underlying mechanism is unclear. The explanation for this phenomenon might help to further simplify LAMP operation. In addition, the LAMP assay has a high rate of false positives, it has strict environmental requirements, and it may easily be contaminated. These factors have slowed the rate of adoption of the LAMP technique. However, as long as the standard LAMP procedure is performed according to the requirements, contamination can effectively be avoided.

In conclusion, the Salmonella LAMP-LFD detection method developed in this study had several advantages over the traditional LAMP method. It was faster and more convenient than the traditional culture detection method. The use of LAMP-LFD might save time and manpower in health centers that test for Salmonella contamination. LAMP-LFD is a novel, rapid and efficient diagnostic tool for the primary identification of Salmonella contamination in the field.

\section{Acknowledgments}

This research was supported by grants from the CoInnovation Center for the High Incidence of Zoonotic Disease Prevention and Control in Western China (No. 2013-179) and the National Natural Science Foundation of China (No. 31360226). The authors would like to express their gratitude to the Laboratory of Zoonosis at Shihezi University for their important contributions. The authors would like to thank Professor Xudong Cao for providing excellent technical support. We thank all of the participants who provided chicken anal swab samples for this study. We would also like to thank LetPub (www.LetPub.com) for providing linguistic assistance during the preparation of this manuscript.

\section{Conflict of interest}

The authors have no financial conflicts of interest to declare.

\section{References}

1. Tang F, Pang DW, Chen Z, Shao JB, Xiong LH, Xiang YP, et al. 2016. Visual and efficient immunosensor technique for advancing biomedical applications of quantum dots on Salmonella detection and isolation. Nanoscale 8: 4688-4698.

2. Lahiri C, Pawar S, Sabarinathan R, Ashraf MI, Chand Y, Chakravortty D. 2014. Interactome analyses of Salmonella pathogenicity islands reveal SicA indispensable for virulence. J. Theor. Biol. 363: 188-197.

3. Vohra P, Bugarel M, Turner F, Loneragan GH, Hope JC, Hopkins J, et al. 2017. Quantifying the survival of multiple Salmonella enterica serovars in vivo using massively-parallel whole genome sequencing to predict zoonotic risk. Appl. Environ. Microbiol. 84: e02262-17.

4. Ji Y, Li W, Zhang Y, Chen L, Zhang Y, Zheng X, et al. 2017. QseB mediates biofilm formation and invasion in Salmonella enterica serovar Typhi. Microb. Pathog. 104: 6-11.

5. Patterson PH, Venkitanarayanan K, Kariyawasam S. 2014. Introduction: reducing Salmonella Enteritidis contamination of shell eggs. J. Appl. Poultry Res. 23: 323-329. 
6. Fatica MK, Schneider KR. 2011. Salmonella and produce: survival in the plant environment and implications in food safety. Virulence 2: 573-579.

7. Rehkopf AC, Byrd JA, Coufal CD, Duong T. 2017. Advanced oxidation process sanitization of hatching eggs reduces Salmonella in broiler chicks. Poult. Sci. 96: 3709-3716.

8. Braden CR. 2006. Salmonella enterica serotype Enteritidis and eggs: a national epidemic in the United States. Clin. Infect. Dis. 43: 512-517.

9. Kim SY, Lee SK, Park MS, Na HT. 2016. Analysis of the fluoroquinolone antibiotic resistance mechanism of Salmonella enterica isolates. J. Microbiol Biotechnol. 26: 1605-1612.

10. Aribam SD, Ogawa Y, Matsui H, Hirota J, Okamura M, Akiba M, et al. 2015. Monoclonal antibody-based competitive enzyme-linked immunosorbent assay to detect antibodies to O:4 Salmonella in the sera of livestock and poultry. J. Microbiol. Methods 108: 1-3.

11. Nde CW, Fakhr MK, Doetkott C, Logue CM. 2008. An evaluation of conventional culture, invA PCR, and the realtime PCR iQ-Check kit as detection tools for Salmonella in naturally contaminated premarket and retail turkey. J. Food Prot. 71: 386-391.

12. Dong J, Zhao H, Xu M, Ma Q, Ai S. 2013. A label-free electrochemical impedance immunosensor based on AuNPs/ PAMAM-MWCNT-Chi nanocomposite modified glassy carbon electrode for detection of Salmonella Typhimurium in milk. Food Chem. 141: 1980-1986.

13. Bell RL, Jarvis KG, Ottesen AR, McFarland MA, Brown EW. 2016. Recent and emerging innovations in Salmonella detection: a food and environmental perspective. Microb. Biotechnol. 9: 279-292.

14. Ohud MAH, Hayam SA, And EMH. 2015. Molecular typing of Salmonella enterica serovars Typhimurium and Enteritidis isolated from Taif area of Saudi Arabia by random amplified polymorphic DNA-polymerase chain reaction (RAPD-PCR). Afr. J. Microbiol. Res. 9: 651-661.

15. Oh SY, Heo NS, Shukla S, Cho HJ, Vilian ATE, Kim J, et al. 2017. Development of gold nanoparticle-aptamer-based LSPR sensing chips for the rapid detection of Salmonella typhimurium in pork meat. Sci. Rep. 7: 10130.

16. Notomi $T$, Okayama $H$, Masubuchi $H$, Yonekawa $T$, Watanabe K, Amino $\mathrm{N}$, et al. 2000. Loop-mediated isothermal amplification of DNA. Nucleic Acids Res. 28: E63.

17. Haridas DV, Pillai D, Manojkumar B, Nair CM, Sherief PM. 2010. Optimisation of reverse transcriptase loop-mediated isothermal amplification assay for rapid detection of Macrobrachium rosenbergii noda virus and extra small virus in Macrobrachium rosenbergii. J. Virol. Methods 167: 61-67.

18. Techathuvanan C, Draughon FA, D'Souza DH. 2010. Loopmediated isothermal amplification (LAMP) for the rapid and sensitive detection of Salmonella Typhimurium from pork. J. Food Sci. 75: M165-172.
19. Lalle M, Possenti A, Dubey JP, Pozio E. 2018. Loopmediated isothermal amplification-lateral-flow dipstick (LAMP-LFD) to detect toxoplasma gondii oocyst in readyto-eat salad. Food Microbiol. 70: 137-142.

20. Tsai SM, Liu HJ, Shien JH, Lee LH, Chang PC, Wang CY. 2012. Rapid and sensitive detection of infectious bursal disease virus by reverse transcription loop-mediated isothermal amplification combined with a lateral flow dipstick. J. Virol. Methods 181: 117-124.

21. Makaraviciute A, Jackson CD, Millner PA, Ramanaviciene A. 2016. Considerations in producing preferentially reduced half-antibody fragments. J. Immunol. Methods 429: 50-56.

22. Ge Y, Wu B, Qi X, Zhao K, Guo X, Zhu Y, et al. 2013. Rapid and sensitive detection of novel avian-origin influenza $\mathrm{A}$ (H7N9) virus by reverse transcription loop-mediated isothermal amplification combined with a lateral-flow device. PLoS One 8: e69941.

23. Huang HL, Zhu P, Zhou CX, He S, Yan XJ. 2017. The development of loop-mediated isothermal amplification combined with lateral flow dipstick for detection of Karlodinium veneficum. Harmful Algae 62: 20-29.

24. Puthawibool T, Senapin S, Flegel TW, Kiatpathomchai W. 2010. Rapid and sensitive detection of Macrobrachium rosenbergii nodavirus in giant freshwater prawns by reverse transcription loop-mediated isothermal amplification combined with a lateral flow dipstick. Mol. Cell. Probes 24: 244-249.

25. Kiatpathomchai W, Jaroenram W, Arunrut N, Jitrapakdee S, Flegel TW. 2008. Shrimp Taura syndrome virus detection by reverse transcription loop-mediated isothermal amplification combined with a lateral flow dipstick. J. Virol. Methods 153: 214-217.

26. Kaewphinit T, Arunrut N, Kiatpathomchai W, Santiwatanakul S, Jaratsing P, Chansiri K. 2013. Detection of Mycobacterium tuberculosis by using loop-mediated isothermal amplification combined with a lateral flow dipstick in clinical samples. Biomed. Res. Int. 2013: 926230.

27. Mahittikorn A, Thammasonthijarern N, Roobthaisong A, Udonsom R, Popruk S, Siri S, et al. 2017. Development of a loop-mediated isothermal amplification technique and comparison with quantitative real-time PCR for the rapid visual detection of canine neosporosis. Parasit Vectors 10: 394.

28. Lee N, Kwon KY, Oh SK, Chang HJ, Chun HS, Choi SW. 2014. A multiplex PCR assay for simultaneous detection of Escherichia coli O157:H7, Bacillus cereus, Vibrio parahaemolyticus, Salmonella spp., Listeria monocytogenes, and Staphylococcus aureus in Korean ready-to-eat food. Foodborne Pathog. Dis. 11: $574-580$.

29. Wang F, Jiang L, Ge B. 2012. Loop-mediated isothermal amplification assays for detecting shiga toxin-producing Escherichia coli in ground beef and human stools. J. Clin. Microbiol. 50: 91-97.

30. Wang X, Ying S, Wei X, Yuan J. 2017. Development of a gold nanoparticle-based universal oligonucleotide microarray 
for multiplex and low-cost detection of foodborne pathogens. Int. J. Food Microbiol. 253: 66-74.

31. Wu GP, Chen SH, Levin RE. 2015. Rapid real-time loopmediated isothermal amplification combined with coated activated carbon for detection of low numbers of Salmonella enterica from lettuce without enrichment. Food Control. 56: 47-52.

32. Yamazaki W, Taguchi M, Kawai T, Kawatsu K, Sakata J, Inoue $\mathrm{K}$, et al. 2009. Comparison of loop-mediated isothermal amplification assay and conventional culture methods for detection of Campylobacter jejuni and Campylobacter coli in naturally contaminated chicken meat samples. Appl. Environ. Microbiol. 75: 1597-1603.

33. Yang Q, Domesle KJ, Wang F, Ge B. 2016. Rapid detection of Salmonella in food and feed by coupling loop-mediated isothermal amplification with bioluminescent assay in realtime. BMC Microbiol. 16: 112.

34. Higuchi R, Fockler C, Dollinger G, Watson R. 1993. Kinetic PCR analysis: real-time monitoring of DNA amplification reactions. Biotechnology (N Y) 11: 1026-1030.

35. Ahern H. Convenient, performance-boosting products put PCR on the fast track - the scientist - magazine of the life sciences. Scientist 10.

36. Xu G, Hu L, Zhong H, Wang H, Yusa S, Weiss TC, et al. 2012. Cross priming amplification: mechanism and optimization for isothermal DNA amplification. Sci. Rep. 2: 246.

37. Barbour EK, Ayyash DB, Alturkistni W, Alyahiby A, Yaghmoor S, Iyer A, et al. 2015. Impact of sporadic reporting of poultry Salmonella serovars from selected developing countries. J. Infect. Dev. Ctries 9: 1-7.

38. Nurul Najian $A B$, Engku Nur Syafirah EA, Ismail $N$, Mohamed M, Yean CY. 2016. Development of multiplex loop mediated isothermal amplification (m-LAMP) labelbased gold nanoparticles lateral flow dipstick biosensor for detection of pathogenic Leptospira. Anal. Chim. Acta 903: 142-148.

39. Abdel-Aziz NM. 2016. Detection of Salmonella species in chicken carcasses using genus specific primer belong to invA gene in Sohag city, Egypt. Vet. World 9: 1125-1128.
40. Hoenigl M, Prattes J, Spiess B, Wagner J, Prueller F, Raggam RB, et al. 2014. Performance of galactomannan, beta-d-glucan, Aspergillus lateral-flow device, conventional culture, and PCR tests with bronchoalveolar lavage fluid for diagnosis of invasive pulmonary aspergillosis. J. Clin. Microbiol. 52: 2039-2045.

41. Mashooq M, Kumar D, Niranjan AK, Agarwal RK, Rathore R. 2016. Development and evaluation of probe based real time loop mediated isothermal amplification for Salmonella: A new tool for DNA quantification. J. Microbiol. Methods 126: 24-29.

42. Kokkinos PA, Ziros PG, Bellou M, Vantarakis A. 2014. Loop-Mediated Isothermal Amplification (LAMP) for the Detection of Salmonella in Food. Food Analytical Methods 7: 512-526.

43. Demeke T, Jenkins GR. 2010. Influence of DNA extraction methods, PCR inhibitors and quantification methods on real-time PCR assay of biotechnology-derived traits. Anal. Bioanal. Chem. 396: 1977-1990.

44. Lu YP, Cheng J, Jiang SF, Zhang LW, Gao ZY, Han B, et al. 2010. Development of multiple quantitative fluorescent PCR for rapid diagnosis of common aneuploidy and it's clinical application. Yi Chuan 32: 1141-1146.

45. Wang C, Shen X, Lu J, Zhang L. 2013. Development of a reverse transcription-loop-mediated isothermal amplification (RT-LAMP) system for rapid detection of HDV genotype 1. Lett. Appl. Microbiol. 56: 229-235.

46. Domesle KJ, Yang Q, Hammack TS, Ge B. 2018. Validation of a Salmonella loop-mediated isothermal amplification assay in animal food. Int. J. Food Microbiol. 264: 63-76.

47. Iseki H, Alhassan A, Ohta N, Thekisoe OM, Yokoyama N, Inoue $\mathrm{N}$, et al. 2007. Development of a multiplex loopmediated isothermal amplification (mLAMP) method for the simultaneous detection of bovine Babesia parasites. J. Microbiol. Methods 71: 281-287.

48. Wong YP, Othman S, Lau YL, Son R, Chee HY. 2017. Loop mediated isothermal amplification (LAMP): a versatile technique for detection of microorganisms. J. Appl. Microbiol. 300: 83-89. 